Motrivivência v. 29, n. 50, p. 62-76, maio/2017

\title{
O JOGO DE VIDEOGAME RELACIONADO AO ATLETISMO E SUAS POSSIBILIDADES PEDAGÓGICAS
}

\author{
Guilherme Correa Comuci ${ }^{\top}$ \\ Sara Quenzer Matthiesen ${ }^{2}$ \\ Guy Ginciene 3
}

\begin{abstract}
RESUMO
Não há dúvidas de que as Tecnologias da Informação e Comunicação (TIC) fazem, cada vez mais, parte do cotidiano, requerendo que diferentes áreas do conhecimento, a exemplo da Educação Física, pensem em como utilizá-las. Diante disso, o objetivo deste artigo foi o de analisar o jogo de videogame Kinect Sports (Xbox 360), relacionado ao atletismo, verificando as proximidades e distanciamentos em relação à modalidade esportiva oficial e suas possibilidades pedagógicas. Foram duas as etapas desta pesquisa: coleta de dados (método visual e observação participante) e análise temática dos dados. Para fins didáticos, os resultados foram apresentados por prova do atletismo analisada, sendo que cada qual foi analisada de acordo com as categorias: descrição, comparações e possibilidades pedagógicas. O videogame pode ser um importante aliado do professor de Educação Física, já que, além de consistir em uma estratégia diferente, poderá contribuir para a exploração do universo do atletismo.
\end{abstract}

Palavras-chave: Educação Física; Tecnologia da Informação e Comunicação; Videogame; Atletismo; Ensino

1 Graduando em Educação Física. Universidade Estadual Paulista (UNESP). Rio Claro/São Paulo, Brasil.

E-mail: guilherme_camuci@hotmail.com

2 Doutora em Educação. Professora do Departamento de Educacão Física da Universidade Estadual Paulista (UNESP). Rio Claro/São Paulo, Brasil. E-mail: saraqm@rc.unesp.br

3 Doutor em Desenvolvimento Humano e Tecnologias. Professor do curso de Licenciatura em Educação Física da Escola Superior de Tecnologia e Educacão de Porto Ferreira (Asser). Porto Ferreira/São Paulo, Brasil.

E-mail: guy_ginciene@hotmail.com 
V. $29, \mathrm{n}^{\circ}$ 50, maio/2017

\section{INTRODUÇÃO}

As Tecnologias da Informação e Comunicação (TIC) fazem, cada vez mais, parte do cotidiano, influenciando a forma com que acessamos as informações e nos comunicamos (KENSKI, 2003; MATTAR; VALENTE, 2007; MORAN, 1997). Isso se potencializa em relação às novas gerações, que já nascem nessa cultura digital, utilizando-a, cada vez mais, em seu dia a dia (CHAMPANGNATTE; NUNES, 2011; RIDEOUT; FOEHR; ROBERTS, 2010; UUSIAUTTI; MÄ̈̈TT̈̈, 2014).

Não à toa, diferentes áreas do conhecimento devem pensar em como utilizá-las, em função de seus inúmeros benefícios. Na Educação Física Escolar, alvo de reflexão neste artigo, não poderia ser diferente, de modo que pensar em formas de utilizá-las em sala de aula como um recurso de ensino (BIANCHI; PIRES, 2010; FAGANELLO, 2008; FERREIRA, 2014; FRANCO, 2014; GERMANO, 2015; MATTHIESEN, 2014; MILANI, 2015), tanto quanto um tema a ser discutido (BETTI, 1997, 2001; DINIZ; RODRIGUES; DARIDO, 2012; GINCIENE; MATTHIESEN, 2014, 2015; LINES, 2007), revela a potencialidade desta discussão, sobretudo, por ser nítido o quanto grande parte do conteúdo desta área já estar presente nas TIC (LINES, 2007), seja por meio dos vídeos, imagens e notícias acessíveis pelos mais diferentes recursos (smartphones, tablets e computadores), como pelo videogame.

Este último, inclusive, é uma ferramenta muito popular entre crianças e jovens, como bem observa Lobo (2014b), baseado em dados da ESPN sobre o jogo de futebol "FIFA 14" e "FIFA 15", que têm ajudado na popularização desta modalidade esportiva nos Estados Unidos da América (LOBO, 2014) ou da constatação de Ferreira e Darido (2013) em relação à utilização de "jogos eletrônicos" relacionados aos esportes entre alunos por elas pesquisados, demonstrando ser esta uma área com um número crescente em pesquisas (COSTA; BETTI, 2006; FERREIRA; DARIDO, 2013; FERREIRA, 2014; FRANCO, 2014).

Contudo, a forte e produtiva ligação entre as Tecnologias da Informação e Comunicação e a Educação Física não pára por aí, mas, se vê referenciada em outras instâncias, a exemplo do Caderno Didático de Educação Física do Estado de São Paulo da 3ª série do Ensino Médio, regido pelo Currículo, em especial, no tema "Corpo na contemporaneidade: a virtualização do corpo e os jogos virtuais - videogames e jogos de botão" (SÃO PAULO, 2014, p. 14).

Outros exemplos desta ligação estão nos trabalhos de Costa e Betti (2006), responsável pela análise das "possibilidades de correlação entre o jogo e as mídias" propondo uma "transformação/transferência do virtual/virtualidade em uma possível experiência corporal educativa na escola na forma de jogos, a partir dos 'jogos virtuais' conhecidos dos alunos" (COSTA; BETTI, 2006, p. 165) e no de Ferreira (2014), que comprovou ser o videogame uma ferramenta interessante para o ensino de conteúdos da Educação Física na escola. Nessa mesma linha, Franco (2014) construiu e aplicou um videogame específico para a Educação Física Escolar, constatando o prazer dos alunos durante as atividades, evidenciando ser o videogame uma ferramenta capaz de auxiliar os professores em suas aulas.

Diante o potencial desse recurso em termos pedagógicos, observamos que dentre os diversos videogames existentes, há um que merece especial destaque, visto que utiliza os 
movimentos do corpo para a realização do jogo. Falamos do Kinect para Xbox 360, lançado em 2010 e que pode ser jogado, apenas com o movimento do corpo, isto é, sem o uso de controles manuais. Um dos jogos para esse videogame é o Kinect Sports que, entre outras possibilidades, possui provas do atletismo (corrida de velocidade, corrida com barreiras, salto em distância, lançamento do dardo e lançamento do disco). Assim, tendo em vista a baixa difusão dessa modalidade esportiva nas escolas (CALVO; MATTHIESEN, 2011, 2012; MATTHIESEN, 2007; MOTA E SILVA et al., 2015) e o potencial de popularização dos esportes por meio dos videogames (LOBO, 2014), percebemos a necessidade de um olhar pedagógico para o Kinect Sports, verificando-se suas possibilidades pedagógicas.

\section{OBJETIVO}

Analisar o jogo de videogame Kinect Sports (Xbox 360), relacionado ao atletismo, verificando as proximidades e distanciamentos em relação à modalidade esportiva oficial e suas possibilidades pedagógicas.

\section{MÉTODOS}

Essa pesquisa de caráter qualitativo (SPARKES; SMITH, 2014; SPARKES, 2013; THOMAS; NELSON; SILVERMAN, 2012), em que se buscou analisar o jogo Kinect Sports do videogame Xbox 360, foi dividida em duas etapas: coleta de dados (método visual e observação participante) e análise dos dados.

\section{$1^{\mathrm{a}}$ etapa: coleta de dados}

Por se tratar de um videogame no qual o controle é o movimento corporal, utilizamos duas técnicas para a coleta de dados. A primeira delas foi a técnica de coleta de dados visuais (GRIFFIN, 2010; SPARKES; SMITH, 2014), restringindo-nos à análise do que aparecia na tela da televisão, ou seja, das imagens produzidas pelo jogo, sendo que todas essas interpretações foram registradas em um caderno de campo (SPARKES; SMITH, 2014).

Num segundo momento, para coletar os dados da vivência do jogo, por meio dos movimentos corporais, utilizamos a observação participante (SPARKES; SMITH, 2014). Nessa etapa, um dos pesquisadores vivenciou repetidas vezes cada uma das provas do atletismo disponível no jogo e, por meio da observação participante, coletou os dados dessa vivência, registrando-os em um caderno de campo (SPARKES; SMITH, 2014).

\section{$2^{\text {a }}$ etapa: análise dos resultados}

Os dados coletados durante a pesquisa, registrados no diário de campo, passaram pela análise temática (BARDIN, 2011; SPARKES; SMITH, 2014), a qual foi realizada em 
6 fases, como descreve Sparkes e Smith (2014). Na $1^{\text {a }}$ fase, realizamos uma imersão nos dados, nesse caso, na leitura das anotações do caderno de campo. Depois disso, na $2^{\mathrm{a}}$ fase, geramos os códigos, por meio do que Bardin (2011) denomina como "unidades de registro temática", concentrando registros de trechos sobre o mesmo assunto. $\mathrm{Na} 3^{\text {a }}$ fase, procuramos e identificamos os temas destes códigos identificados na fase anterior, enquanto que na $4^{\text {a }}$ fase revisamos esses temas para termos certeza de que todos foram abrangidos. Na $5^{\text {a }}$ fase, definimos os nomes de cada tema, como segue: "descrição" (do jogo e de como se joga); "comparações" (entre o jogo e a prova oficial) e "possibilidades pedagógicas" (como o professor poderia utilizar o jogo em suas aulas. Por fim, na $6^{\mathrm{a}}$ fase, apresentamos e analisamos os resultados.

\section{RESULTADOS}

Para fins didáticos, os resultados desta pesquisa serão apresentados por prova analisada, portanto, de acordo com o que segue: corrida de velocidade (100 metros rasos); corrida com barreiras; salto em distância; lançamento do dardo e lançamento do disco. Em cada tópico relacionado à prova será apresentado e discutido os resultados segundo os temas encontrados na análise, quais sejam: descrição, comparações e possibilidades pedagógicas.

\section{Corrida de Velocidade}

\section{Descrição}

A corrida de velocidade do Kinect Sports é representada pela prova dos 100 metros rasos. Neste jogo de videogame, essa prova tem início com uma saída alta, apesar de haver bloco de partida. Após a largada, os personagens ${ }^{4}$, da mesma forma que em uma prova oficial, correm em raias individuais até a linha de chegada.

Para jogar, basta "correr no lugar", elevando-se os joelhos, assim que se ouvir o comando de largada, sem que haja a necessidade de realização da saída baixa. Quanto mais rápido for esse movimento, mais rápido o personagem do jogo correrá.

\section{Comparações}

Na prova oficial dos 100 metros rasos, a largada é feita por meio da saída baixa com os pés apoiados no bloco de partida, enquanto que neste jogo, os personagens fazem a saída alta, ou seja, em pé. Em ambos os casos, os atletas 5 /personagens correm em sua própria raia até a linha de chegada.

4 A palavra "personagem" será utilizada neste texto para referência ao atleta do jogo, ou seja, àquele que aparece no visor, de forma virtual.

5 A palavra "atleta" será utilizada neste texto para referência àquele que pratica o atletismo. 
Analisando a prova da corrida dos 100 metros rasos apresentada pelo videogame e uma prova oficial disputada atualmente em competições de atletismo, nota-se que há algumas diferenças em relação aos aspectos relacionados às regras. Por exemplo, segundo CBAt (2014, p. 58), nas "corridas até e inclusive os 400m [...], é obrigatório a saída em posição agachada e o uso de blocos de partida", enquanto que no jogo de videogame não há obrigatoriedade na utilização do bloco de partida, tanto que o jogador ${ }^{6}$, ao dar a partida, não precisa executar a saída baixa propriamente dita. O videogame apenas indica o movimento de corrida no lugar, com elevação dos joelhos.

Ainda em relação à largada, de acordo com a CBAt (2014, p. 58), os comandos são: "Às suas marcas" e "Prontos", seguido pelo tiro de largada. Já no jogo, o árbitro menciona, em inglês, apenas o comando de: "Às suas marcas".

Entretanto, o jogo respeita as regras oficiais no que se refere à realização da corrida de velocidade em uma raia pré-definida, assim como ocorre no jogo e é previsto pela CBAt (2014): “Em todas as corridas realizadas em raias marcadas, cada Atleta deverá manter-se em sua raia designada do início ao fim. Isso se aplica a qualquer parte de uma prova corrida em raias marcadas" (p. 59).

A análise também revela que o recorde dos 100 metros rasos do jogo é de 12", sendo que no ano em que o videogame foi lançado, 2010, o recorde masculino oficial da prova era de 9,69" e pertencia ao jamaicano Usain Bolt. Hoje, o recorde dos 100 metros rasos é 9,58" e pertence ao mesmo atleta, enquanto que o recorde mundial feminino é de 10'49" pertencendo a Florence Griffith-Joyner. Dessa forma, no videogame, caso ocorra uma execução correta dos movimentos, é possível se alcançar um tempo menor que o recorde oficial atual.

\section{Possibilidades pedagógicas}

Com base nas observações anteriores e pensando na utilização deste videogame em aulas de Educação Física, o professor poderá, por exemplo, abordar aspectos relacionados à largada das corridas (regras, técnicas e história), a técnica e aos aspectos conceituais (recordes e conhecimentos gerais de uma pista de atletismo).

Em relação à largada, o professor poderá aproveitar para explicar e discutir com os alunos as regras e a técnica das corridas, evidenciando as diferenças entre a saída alta (realizada no videogame) e a saída baixa. Este é um momento oportuno para explicar aos alunos que a saída alta, realizada no videogame, é utilizada em corridas de meio fundo e fundo em competições oficiais de atletismo, enquanto que a saída baixa é obrigatória nas corridas de velocidade. Diante disso, os alunos podem vivenciar e experimentar as duas formas de largada, além de conhecer e vivenciar parte de sua história e de suas regras (GINCIENE; MATTHIESEN, 2009, 2012a, 2012b; MATTHIESEN; GINCIENE, 2013; MATTHIESEN, 2007, 2014).

6 A palavra "jogador" será utilizada neste texto para referência àquele que está jogando, ou seja, que está controlando o personagem do videogame. 
Para além disso e com base nas imagens relacionadas à pista de atletismo apresentadas pelo videogame, o professor poderá ensinar sobre o local em que é disputada a prova dos 100 metros rasos, enfatizando, por exemplo, o porquê da existência das raias em provas como esta.

A discussão sobre o recorde da prova poderá ser realizada com base na comparação entre o recorde oficial (masculino ou feminino) e o tempo registrado pelo jogador durante o jogo. Durante a partida, o professor poderá solicitar aos alunos que anotem quais são as diferenças das regras que eles visualizaram durante a execução do jogo, comparando-as com as regras oficiais da prova, por exemplo.

Pensando na parte técnica da corrida, em que o atleta deve elevar os joelhos para correr, nota-se que o videogame, no que se refere à corrida dos 100 metros rasos, pode ser bastante útil. Consultando a bibliografia da área, nota-se que este é um aspecto importante, já que: "Alguns educativos são mais utilizados por velocistas, por barreiristas e por saltadores durante seus treinamentos" (MATTHIESEN, 2007, p.39), como é o caso da elevação dos joelhos, própria do skipping. Isso pode favorecer a execução do movimento da corrida, quando da realização em aulas práticas de Educação Física, que envolvam as corridas de velocidade, por exemplo.

\section{Corrida com Barreiras}

Descrição

A corrida com barreiras do Kinect Sports, assim como nos 100 metros rasos, apresenta o bloco de partida apesar da realização da saída alta. Os personagens fazem a largada ao ouvirem o comando do árbitro. A transposição da barreira é feita com a técnica correta, ou seja, com uma perna estendida e outra flexionada.

Para correr, o jogador apenas eleva os joelhos e corre no lugar. Para transpor a barreira, o jogador apenas salta no lugar quando esta fica verde na tela, indicando que deve ser saltada. O importante é que saia do chão, sendo que não precisa, necessariamente, realizar o movimento oficial.

\section{Comparação}

Nas corridas com barreiras oficiais (100, 110 e 400 metros), a largada é feita por meio da saída baixa, com os pés apoiados no bloco de partida (CBAT, 2014; IAAF, 2015), enquanto que, no jogo, os personagens fazem a saída alta.

Em relação à fase da corrida, no videogame, assim como na prova oficial, os competidores correm em sua própria raia até a linha de chegada. Na prova oficial, o atleta transpõe a barreira com a técnica correta, ou seja, com uma perna estendida e a outra flexionada, voltada para trás, de forma a passar rapidamente por ela (MATTHIESEN, 2007, 2014). Nota-se que o personagem do videogame executa o movimento de forma correta. 
No entanto, para jogar, o jogador deve apenas sair do chão, sem se preocupar com a execução do movimento.

Com relação à distância da prova, verificamos que a do videogame não corresponde a uma distância oficial de corridas com barreiras, ou seja, 100 metros (feminino), 110 metros (masculino) e 400 metros (masculino e feminino) (CBAT, 2014; IAAF, 2015; MATTHIESEN, 2005, 2007, 2014). A prova no videogame não respeita essas distâncias, já que a mesma tem início no final da última curva, antes da reta final, passando a impressão de ter 200 metros.

Outro ponto que merece destaque na análise dessa prova corresponde à quantidade de barreiras existentes no videogame. De acordo com as regras oficiais, devem existir 10 barreiras em cada raia, independente da distância da prova (100, 110 ou 400 metros) (CBAT, 2014; IAAF, 2015), o que não acontece no videogame, que possui apenas 4 barreiras.

Possibilidades pedagógicas

Assim como nos 100 metros rasos, o professor poderá solicitar aos alunos que realizem a saída baixa e corram normalmente como no videogame. Além disso, o professor poderá ensinar os movimentos da perna de "passagem" e da "perna de ataque" (MATTHIESEN, 2007) e pedir para que realizem esse movimento durante o jogo, ao invés de saltarem para cima e com os dois pés.

Por fim, durante a partida de videogame, o professor poderá solicitar aos alunos que anotem quais são as diferenças das regras que eles encontraram durante a execução, tais como: tamanho da prova, forma de correr, saída baixa, raias etc.

\section{Salto em Distância}

Descrição

O jogo tem início com o personagem pronto para realizar o salto em distância, sem a necessidade de esperar o sinal do árbitro para iniciar a corrida e, posteriormente, o salto. Nessa prova, os movimentos demonstram ser bem fiéis aos da prova oficial do salto em distância. Ao chegar perto da tábua de impulsão, o videogame mostra o personagem fazendo o salto em distância, realizando o estilo "passada no ar"(MATTHIESEN, 2005, 2007, 2014).

Para jogar, deve-se levantar o joelho e "correr no lugar" para iniciar a fase de corrida. Para saltar, é preciso utilizar os dois pés, saltando para cima quando o chão ficar verde (área de salto). O jogador não precisa fazer o movimento do salto para frente, apenas, para cima no momento certo.

\section{Comparação}

Na prova oficial do salto em distância, o atleta corre pelo corredor de saltos, até chegar na tábua de impulsão, sendo que com a "perna de impulsão", ele salta em direção à caixa de areia realizando um dos estilos do salto (grupado, arco ou passada no 
ar) (MATTHIESEN, 2005, 2007, 2014). No jogo, o personagem também realiza o impulso com uma das pernas, como exigido pela regra oficial (CBAT, 2014; IAAF, 2015), porém, o jogador que controla o personagem pode saltar com as duas ou com apenas uma perna, já que o importante é o movimento do salto. Outra diferença, é que o jogador deve saltar apenas para cima e não para frente como ocorre quando se utiliza uma das técnicas do salto em distância (grupado, arco ou passada no ar). Apesar de ter que saltar para cima, no videogame é mostrado o personagem realizando o movimento do salto "passada no ar", também conhecido como hitch kick, o qual pode ser assim descrito:

A partir de um movimento de alternância entre pernas e braços após a impulsão, o saltador realiza uma passada e meia no ar (alguns saltadores chegam a realizar duas passadas e meia) antes de finalizar o salto com a queda (MATTHIESEN, 2007, p. 110).

No videogame, ao chegar o momento da realização do salto, o chão do corredor fica verde. Caso o jogador não salte nessa hora, o personagem passa pela tábua de impulsão e falha na tentativa de salto. De acordo com a CBAt (2014, p. 78), o atleta falha se "ao dar impulsão ele toca o solo além da linha de impulsão com qualquer parte de seu corpo, quer passe correndo sem saltar quer no ato de saltar", reforçando, portanto, que o salto será invalidado, assim como ocorre no videogame.

Também pode ser observado que após a realização do salto, o personagem deixa a caixa de areia pela frente, reforçando a regra oficial que prevê que:

Quando deixar a área de queda, o primeiro contato de um Atleta com os pés na borda ou no solo do lado de fora, deverá ser o mais afastado da linha de impulsão do que a marca mais próxima na areia (que pode ser qualquer marca feita em desequilíbrio completamente dentro da área de queda e ao retornar volta mais perto da linha de impulsão que a marca inicial na queda) (CBAt, 2014, p.78).

Possibilidades pedagógicas

Durante a partida de videogame, o professor poderá solicitar aos alunos que anotem quais são as diferenças das regras que eles encontraram durante a execução, tais como: local de salto, arbitragem, movimento/estilo de salto etc.

Além disso, não há menção ao recorde oficial de 8,95 metros, pertencente a Mike Powell e de 7,52 pertencente a Galina Christyakova, fato que poderia ser abordado pelo professor de Educação Física, ampliando o conhecimento dos alunos.

\section{Lançamento do Dardo}

Descrição

No jogo, o personagem corre em linha reta, segurando o dardo em sua mão de preferência. Quando o jogador faz o movimento de lançar, movimentando o braço para 
trás e para frente, por cima do ombro, o personagem executa o lançamento do dardo. Logo, o jogador deve escolher com qual dos braços será feito o lançamento (esquerdo ou direito), "correndo no lugar", com elevação dos joelhos até que o chão fique verde, o que significa que deve executar o lançamento. Se essa área verde for ultrapassada, o lançamento é considerado falho. Quanto melhor o movimento, mais longe o dardo irá.

\section{Comparação}

A primeira comparação que pode ser feita entre o videogame e uma prova oficial é de ordem conceitual. Nota-se que, desde o início da prova, o videogame repete, muitas vezes, instruções para se arremessar o dardo, quando o correto seria lançar o dardo, já que arremesso é apenas utilizado para a prova do arremesso do peso (MATTHIESEN, 2005, 2007, 2014).

Em relação aos movimentos, nota-se que o atleta inicia uma prova oficial correndo em linha reta, antes de executar a técnica da passada cruzada que dará início a fase final do lançamento (MATTHIESEN, 2005, 2007, 2014). No jogo, o personagem apenas corre em linha reta até o momento do lançamento.

Analisando a prova no que se refere às regras, nota-se que assim como prevê a regra oficial do lançamento do dardo - ou seja, que: “Um lançamento é válido somente se a cabeça metálica do dardo tocar o solo antes que qualquer outra parte" (CBAt, 2014, p.88) - o jogo demonstra que o dardo, ao tocar o solo do setor de queda, toca sua cabeça metálica primeiro. Entretanto, pela regra oficial, não há necessidade de que o dardo finque no solo, como demonstra o jogo. Basta, apenas, que ele toque a cabeça metálica primeiro.

De acordo com a CBAt (2014, p. 88), o:

[...] dardo deve ser seguro na empunhadura somente com uma das mãos. Será lançado por sobre o ombro ou acima da parte superior do braço de lançamento e não deve ser lançado com movimentos rotatórios. Estilos não ortodoxos não são permitidos (p. 88).

No jogo, nota-se que é permitido que o jogador utilize movimentos não ortodoxos, como, por exemplo, realizar o lançamento de baixo para cima, fato que merece correção, já que pela regra oficial: "Estilos não ortodoxos não são permitidos" (CBAT, 2014, p.88).

Outro ponto que pode ser evidenciado neste jogo está relacionado ao número de tentativas na fase classificatória. Segundo a CBAt (2014, p. 90): "No salto em distância e cada uma das provas de arremesso/lançamentos, serão permitidas somente 3 tentativas a cada Atleta". Nessa prova do videogame, quando o dardo não ultrapassa o arco do setor de lançamento, é dada mais uma chance para a realização do lançamento, permitindo ao jogador mais que 3 tentativas. Numa competição oficial, isso apenas ocorreria caso houvesse menos que 8 atletas, os quais, segundo Matthiesen (2007), teriam, então, possibilidade de executar 6 tentativas, disputando a final da prova.

No videogame, o jogador deverá correr antes de realizar o movimento de lançamento, mas, caso ultrapasse a área indicada no visor, seu lançamento será invalidado. Isso respeita a regra oficial da prova, ou seja: "O lançamento deverá ocorrer sem que o 
lançador ultrapasse o arco do setor de lançamento (de madeira ou metal) fixado no solo ao final do corredor" (MATTHIESEN, 2007, p. 156).

Outro ponto que invalida o lançamento no videogame é quando o dardo ultrapassa o setor de queda. Na regra oficial desta prova, observamos que:

A cabeça do dardo obrigatoriamente deverá cair dentro do setor de queda de modo que a medição ocorrerá a partir do local em que a ponta de metal tocar o solo pela primeira vez até a borda interna do arco ao longo de uma linha que vai desde o local de queda até o centro do círculo de que o arco faz parte (MATTHIESEN. 2007, p.156)

Assim, o videogame reforça a importância de que o dardo caia dentro do setor de queda para validar o lançamento, conforme ocorre em provas oficiais de atletismo.

No jogo, o recorde é de 46 metros, enquanto que o recorde masculino atual é de 98,48 metros e pertence a Jan Zalezny e o feminino é de 72,28 metros, pertencendo a Barbora Spotáková.

Possibilidades pedagógicas

Pensando nas possibilidades pedagógicas relacionadas à utilização desta prova do videogame em aulas de Educação Física, o professor poderia ensinar, por exemplo, as três empunhaduras existentes no dardo (estilo garfo, estilo finlandesa e estilo americano) e pedir para que o aluno utilize uma delas durante a realização da prova.

Poderia, também, ensinar a passada cruzada, solicitando aos alunos que a realizem durante a corrida de aproximação. Além disso, poderia comparar o movimento da passada cruzada com o movimento da corrida, solicitado pelo videogame, que não contempla a passada cruzada antes do lançamento.

De qualquer forma, o professor deverá ensinar aos alunos apenas os estilos permitidos pelas regras oficiais, excluindo os estilos não ortodoxos, conforme prevê a regra oficial da prova, conforme mencionamos anteriormente.

Além disso, durante as aulas pode-se fazer referência ao recorde atual da prova, isto é, de 98,48m, pertencente a Jan Zalezny (masculino) e de 72,28n, pertencente a Barbora Spotáková (feminino), relacionando-os ao recorde mencionado pelo jogo, 46 metros, a fim de discutir as diferenças existentes entre eles.

Uma outra opção pedagógica é solicitar, durante a partida do videogame, que os alunos anotem as diferenças entre as regras, a execução, o estilo da corrida, o local de lançamento, as diferenças no dardo etc.

\section{Lançamento do Disco}

Descrição

No videogame, a prova do lançamento do disco é realizada pelo personagem de forma bastante simples, utilizando-se um pequeno movimento de rotação do troco, acompanhado pelo braço, levando-se o disco de trás para frente. 
Para jogar, deve-se escolher com qual dos braços o movimento será realizado. Feito isso, o jogador deve realizar o balanceio, movimentando os braços de um lado para o outro (como na prova oficial) para lançar o disco. O jogador não precisa fazer o movimento correto do lançamento do disco, mas, deve, apenas, realizar o balanceio de um lado para o outro, de forma rápida. Se o braço estiver muito baixo, o disco sairá de maneira errada, podendo invalidar a tentativa e/ou bater na gaiola.

\section{Comparação}

Assim como ocorre no lançamento do dardo - mencionado no videogame como "arremesso" do dardo - a prova do lançamento do disco aparece no videogame como "arremesso de disco".

Em relação aos movimentos, no videogame é solicitado ao jogador que realize o balanceio na preparação para o lançamento. Esse é um movimento técnico importante da prova oficial, assim como descrito por Matthiesen (2007, p. 166): “Partindo de uma posição estacionária, o lançador iniciará os balanceios, movimentando o disco de um lado para o outro, com o intuito de preparar-se para a realização do (s) giro (s) e do lançamento". Apesar disso, no videogame, tanto o jogador quanto o personagem do jogo não realizam os giros, cujo movimento é mais aprimorado e utilizado, normalmente, por atletas de alto nível.

Já em relação às regras, no videogame, essa prova ocorre dentro da gaiola de proteção, o que valoriza o ensino correto dessa prova, prevendo os cuidados que ela exige, já que, de acordo com a CBAt (2014, p. 84): “Todos os lançamentos do disco devem ser efetuados dentro de uma proteção ou gaiola para garantir a segurança dos espectadores, árbitros e Atletas". Além disso, o personagem do videogame realiza o lançamento dentro do círculo de lançamento, assim como ocorre em uma competição oficial.

O recorde da prova no jogo é de 38 metros, enquanto que o recorde mundial masculino é de 74,08 metros e pertence a Jurgen Schult, enquanto que o feminino é de 76,80 e pertence a Gabriele Reinsch.

\section{Possibilidades pedagógicas}

Com base nas observações anteriores, o professor poderia simular o local do lançamento do disco fazendo um desenho no chão, a partir do qual os alunos realizariam o movimento do lançamento.

Feito isso, poderia solicitar aos alunos que realizassem os movimentos solicitados pelo videogame como se fosse uma prova oficial, ou seja, primeiramente com o balanceio, com a mão voltada para baixo, como na prova oficial. Ou seja, como Matthiesen (2007) explica "[...] o lançador realiza a empunhadura segurando o disco com as falanges distais de sua mão dominante" (p. 166). Ainda segundo Matthiesen (2007): "o lançador iniciará os balanceios, movimentando o disco de um lado para o outro" (p. 166). 
Em relação à técnica, considerando que os movimentos utilizados no videogame são os básicos, necessários para a realização da prova, entendemos que sua utilização poderá contribuir para o ensino desta prova em aulas de Educação Física.

Durante a partida, o professor poderia solicitar aos alunos que anotassem quais são as diferenças que eles encontraram durante a execução, como por exemplo: estilo do lançamento, local do lançamento etc.

Estas, portanto, são apenas algumas possibilidades pedagógicas encontradas em uma primeira análise do jogo, que demonstram que esse recurso pode contribuir, de fato, para o ensino da Educação Física na escola.

\section{CONSIDERAÇÕES FINAIS}

Por conta da proximidade dos alunos com as tecnologias, nota-se que a utilização do videogame, como uma ferramenta pedagógica em aulas de Educação Física, pode contribuir para o ensino de diferentes conteúdos, a exemplo do atletismo. Entretanto, neste caso, é preciso certo cuidado, considerando-se que as provas apresentadas pelo Kinect Sports do Xbox 360 apresentam, como vimos nesta pesquisa, algumas fragilidades, as quais poderão ser abordadas pelo professor, para que os alunos tenham uma compreensão correta acerca de cada uma dessas provas (corrida de velocidade, corrida com barreiras, salto em distância, lançamento do dardo e lançamento do disco).

Outro ponto que merece ser destacado ao final desta pesquisa e que poderá dificultar a utilização do Kinect Sports do Xbox 360 em aulas de Educação Física, é que a escola precisaria adquirir o aparelho, de modo que, levando em consideração o preço do produto, talvez houvesse dificuldades nessa aquisição.

Além disso, a escola teria que ter um espaço adequado para utilizar o videogame, fato que poderia ser facilmente resolvido destinando-se uma sala de aula para isso. Mas, considerando-se que são várias as turmas/séries numa instituição escolar, o professor/ alunos teriam que transportar todos os equipamentos (Kinect, Xbox e televisão) de uma sala para outra, colocando em risco o equipamento. Talvez, esse problema pudesse ser solucionado colocando-se o equipamento na sala de informática da escola, por exemplo.

Vale a pena lembrar que esse trabalho foi apenas uma análise sobre o Kinect Sports do Xbox 360, apontando algumas de suas possibilidades pedagógicas, visando o ensino do atletismo em aulas de Educação Física na escola, estando certos de que outros trabalhos/ pesquisas poderiam ser desenvolvidos acerca deste tema.

De qualquer forma, concluímos que o videogame pode ser um importante aliado do professor, já que, além de oferecer uma forma de trabalho diferente no universo escolar, fazendo uso das tecnologias, poderá permitir ao professor de Educação Física explorar, cada vez mais, o amplo universo do atletismo. 


\section{REFERÊNCIAS}

BARDIN, L. Análise de Conteúdo. [s.I.] Edições 70, 2011.

BETTI, M. A janela de vidro: esporte, televisão e Educacão Física. [s.l.] Universidade

Estadual de Campinas (UNICAMP), 1997.

BETTI, M. Mídias: Aliadas ou Inimigas da Educação Física Escolar? Motriz Rio Claro,

v. 7, n. 2, p. 125-129, 2001.

BIANCHI, P.; PIRES, G. D. L. Possibilidades Para O Ensino-Aprendizagem Com Tics Na Educação Física Escolar: Caderno de Formação RBCE, v. 1, p. 45-55, 2010.

CALVO, A. P.; MATTHIESEN, S. Q. O atletismo está presente nas aulas de Educação Física Escolar? Revista Digital De Educacion Fisica, v. 16, n. 160, 2011.

CALVO, A. P.; MATTHIESEN, S. Q. Diagnóstico do conteúdo da Educação Física Escolar: o atletismo em foco. Revista Digital De Educacion Fisica, v. 16, n. 164, 2012.

CBAT. ATLETISMO: Regras oficiais de Competicão 2014-2015. [s.l: s.n.].

CHAMPANGNATTE, D. M. D. O.; NUNES, L. C. A inserção das mídias audiovisuais no contexto escolar. Educação em Revista, v. 27, n. 3, p. 15-38, 2011.

COSTA, A. Q. DA; BETTI, M. Mídias e Jogos: do virtual para uma experiência corporal educativa. Revista Brasileira de Ciências do Esporte, v. 27, n. 2, p. 165-178, 2006.

DINIZ, I. K. S.; RODRIGUES, H. A.; DARIDO, S. C. Os usos da midia em aulas de educação fisica escolar: Possibilidades e dificuldades. Movimento, v. 18, n. 3, p. 183-202, 2012.

FAGANELLO, F. R. Análise dos livros de atletismo como subsídio para o seu ensino no campo escolar. [s.l.] UNESP, 2008.

FERREIRA, A. F. Os Jogos digitais como apoio pedagógico nas aulas de Educação Física escolar pautadas no currículo do Estado de São Paulo. [s.I.] UNESP, 2014.

FERREIRA, A. F.; DARIDO, S. C. Os Jogos Eletrônicos no cotidiano dos alunos do $9^{\circ}$ ano do Ensino Fundamental. ETD - Educacão Temática Dogital, v. 15, n. 3, 2013.

FRANCO, L. C. P. Jogos digitais educacionais nas aulas de educação física: Olympia, um videogame sobre os Jogos Olímpicos. [s.I.] UNESP, 2014.

GERMANO, V. A. C. Educação Física escolar e currículo do Estado de São Paulo: possibilidades dos usos do celular como recurso pedagógico no ensino do Hip Hop e Street Dance. [s.I.] UNESP, 2015.

GINCIENE, G.; MATTHIESEN, S. Q. Fragmentos Da História Dos 100 Metros Rasos : Teoria E Prática. Coleção Pesquisa Em Educação Física, v. 8, n. 3, p. 181-186, 2009.

GINCIENE, G.; MATTHIESEN, S. Q. O sistema de partida em corridas de velocidade do atletismo. Motriz Rio Claro, v. 18, n. 1, p. 113-119, 2012a.

GINCIENE, G.; MATTHIESEN, S. Q. Changes over time in the 100-meter dash at the Olympic Games. In: HOFMANN, A. R.; KRÜGER, M. (Eds.). . Olympia als Bildungsidee: Beiträge zur olympischen Geschichte und Pädagogik. [s.I.] Springer-Verlag, 2012b. p. 294.

GINCIENE, G.; MATTHIESEN, S. Q. Deve-se utilizar as Tecnologias da Informação e Comunicação em aulas de Educacão Física? Arquivos em Movimento, v. 10, n. 2, p. 111-128, 2014. 
V. $29, \mathrm{n}^{\circ}$ 50, maio/2017

GINCIENE, G.; MATTHIESEN, S. Q. UTILIZANDO O MOODLE NA EDUCAÇÃO FÍSICA: sobre um material didático virtual para o ensino do atletismo. Motrivivência, v. 27, n. 44, p. 109-124, 2015.

GRIFFIN, M. Setting the scene: hailing women into a running identity. Qualitative Research in Sport and Exercise, v. 2, n. 2, p. 153-174, 2010.

IAAF. Competition Rules 2016-2017 - IAAF. IAAF Athletics, p. 315, 2015.

KENSKI, V. M. Tecnologias E Ensino Presencial E a Distância. [s.I.] Papirus Editora, 2003.

LINES, G. The impact of media sport events on the active participation of young people and some implications for PE pedagogy. Sport Education and Society, v. 12, n. 3, p. 317-334, 2007.

LOBO, F. Fifa no videogame tem feito americanos gostarem mais de futebol. Disponível

em: < http://trivela.uol.com.br/fifa-videogame-americanos-futebol/>. Acesso em: 10 fev. 2016.

MATTAR, J. A.; VALENTE, C. Second life e web 2.0 na educaçao: o potencial revolucionário das novas tecnologias. São Paulo: NOVATEC, 2007.

MATTHIESEN, S. Q. Atletismo se aprende na escola. Jundiaí: Fontoura, 2005.

MATTHIESEN, S. Q. Atletismo: Teoria e Prática. Rio de Janeiro: Guanabara Koogan, 2007.

MATTHIESEN, S. Q. Atletismo na escola. Maringá: Eduem, 2014.

MATTHIESEN, S. Q.; GINCIENE, G. História das corridas. Jundiaí: Fontoura, 2013.

MILANI, A. G. Gênero nas aulas de Educação Física: diálogos possíveis com os conteúdos do currículo do Estado de São Paulo e o Facebook. [s.I.] UNESP, 2015.

MORAN, J. M. Como utilizar a Internet na educação. Ciência da Informação, v. 26, n. 2, p. 1-17, 1997.

MOTA E SILVA, E. V. et al. Atletismo (ainda) não de aprende na escola? Revisitando artigos publicados em periódicos científicos da Educação Física nos últimos anos. Movimento, v. 21, n. 4, p. 1111-1122, 2015.

RIDEOUT, V. J.; FOEHR, U. G.; ROBERTS, D. F. Generaton $\mathbf{M}^{2}$ : Media in the Lives of 8- to 18-Year-OldsA Kaiser Family Foudation Study. [s.I: s.n.].

SPARKES, A. C. Qualitative research in sport, exercise and health in the era of neoliberalism, audit and New Public Management: understandng the conditions for the (im)possibilities of a new paradigm dialogue. Qualitative Research in Sport, Exercise and Health, v. 5, n. 3, p. 440-459, 2013.

SPARKES, A. C.; SMITH, B. Qualitative research methods in Sport, Exercise and Health. London: Routledge, 2014.

THOMAS, J. R.; NELSON, J. K.; SILVERMAN, S. J. Métodos de Pesquisa em Atividade Física. 6a ${ }^{\text {a }}$ ed. [s.l.] Artmed, 2012.

UUSIAUTTI, S.; MÄ̈̈TTÄ, K. I am no longer alone - How do university students perceive the possibilities of social media? International Journal of Adolescence and Youth, v. 19, n. 3, p. 293-305, 2014. 


\title{
VIDEOGAME RELATED TO ATHLETICS AND EDUCATIONAL POSSIBILITIES
}

\begin{abstract}
There are no doubts that Information and Communication Technology (ICT) influence our daily life, requiring that different areas of knowledge, like Physical Education for example, thinks about how to use it. Because of that, the aim of this article was to analyze the game "Kinect Sports" of Xbox 360, about some athletics events, compare it with the official events and identify the pedagogical possibilities. Two steps were organized to do this research: data collection (visual methods and participant observation) and thematic analysis. For a better way of presentation, the results were first organized by the athletics events. Each of those events was analyze with 3 themes: description, comparisons and pedagogical possibilities. The videogame can be an important resource for the Physical Education teacher, because it is a different strategy that can contribute for the exploration of the athletics universe.
\end{abstract}

Keywords: Physical Education; Information and Communication Technology; Videogame; Athletics; Teaching

\section{JUEGO DE VIDEOJUEGO EN MATERIA DE ATLETISMO Y POSIBILIDADES EDUCATIVAS}

\section{RESUMEN}

No hay duda de que las Tecnologías de la Información y Comunicación (TIC) son cada vez más parte de la vida cotidiana, lo que implica para diferentes áreas de conocimiento, como la educación física, pensar en cómo utilizarlas. Por lo tanto, el objetivo de este trabajo fue analizar el videojuego Kinect Sports (Xbox 360), relacionado con el atletismo, comprobando las proximidades y las diferencias en relación con el deporte oficial y sus posibilidades educativas. Se desarrollaron dos etapas en esta investigación: recolección de datos (método visual y observación participante) y el análisis temática de los datos. Para los propósitos didácticos, los resultados se presentan en las pruebas analizada, cada una de las cuales se analizó de acuerdo a: descripción, comparaciones y posibilidades pedagógicas. El juego puede ser un aliado importante del maestro de educación física, ya que además de consistir en una estrategia diferente que puede permitir el exploración del universo de atletismo.

Palabras clave: Educación Física; Tecnología de Información y Comunicación; Video juego; Atletismo; Enseñanza 